\title{
Human(ized) Monoclonal Antibodies in Asthma: Future Perspectives
}

\author{
Arzu Didem Yalcin ${ }^{1,2^{*}}$ \\ ${ }^{1}$ Internal Medicine, Allergy and Clinical Immunology, Academia Sinica, Genomics Research Center, 11529, Taipei, Taiwan \\ ${ }^{2}$ Antalya Education and Research Hospital, Antalya, 07070, Turkey
}

*Corresponding author: Arzu Didem Yalcin, Internal Medicine, Allergy and Clinical Immunology, Academia Sinica, Genomics Research Center, 11529, Taipei, Taiwan, E-mail: adidyal@yahoo.com

Received date: September 21, 2016; Accepted date: September 23, 2016; Published date: September 26, 2016

Copyright: $\odot 2016$ Yalcin AD. This is an open-access article distributed under the terms of the Creative Commons Attribution License, which permits unrestricted use, distribution, and reproduction in any medium, provided the original author and source are credited

Citation: Yalcin AD (2016) Human(ized) Monoclonal Antibodies in Asthma: Future Perspectives. J Allergy Ther 7: e115. doi:10.4172/2155-6121.1000e115

\section{Editorial}

The pathophysiological mechanisms underlying asthma which is an heterogeneous disease, are characterized by interactive responses among various cell types (airway epithelial, smooth muscles cells, mesenchymal cells), and the hematopoietic cells of the adaptive and innate immune systems. Patients with severe persistent asthma (SPA) are at an increased risk of cardiovascular disorder and increased systemic inflammation associated with SPA may play a role. High levels of the proinflammatory mediators ddimer, CXCL8, homocysteine, eosinophil cationic peptide (ECP), IL-6, CRP, and TNF are elevated in SPA, and all are associated with increased cardiovascular risk [1].

Human(ized) monoclonal antibodies (HMA), which make up the vast majority of available biologic agens, are among the fastest-growing therapeutic biologics being developed to treat SPA. By their very nature, HMA have high target specificity. Discriminating the complex systemic inflammatory and regulatory pathways underlying the immunopathogenesis of SPA has allowed the development of potent inhibitors at the cytokine/receptor level. This specific targeting minimizes the risks of side effects [2].

Approved HMA for the treatment of SPA in Phase II studies are as follows ; quilizumab (directed against an extracellular 52-aminoacid segment termed M1 prime of human membrane IgE through reduction of new IgE-producing plasma cells), ligelizumab (Binds C3 domain of IgE), dupilumab (Binds IL-4Ra inhibiting both IL-4 and IL-13 signaling), AMG 317 (AMG 317 is a fully human monoclonal IgG2 antibody to IL- 4R), AMG 157(Human anti-TSLP monoclonal immunoglobulin G2k that specifically binds human TSLP), pitrakinra (Recombinant human IL-4 variant that is a potent inhibitor of both the IL-4 and IL-13 receptors), altrakincept (Soluble recombinant human IL-4 receptor: Phase III study completed), pascolizumab (Humanized $\mathrm{mAb}$ blocking IL- 4), lebrikizumab (IgG4 humanized monoclonal antibody that binds IL-13 with high affinity), tralokinumab (IL-13specific human monoclonal antibody that binds to and neutralizes IL-13: Phase III study ongoing), anrukinzumab (IMA-638 and IMA-026) (Fully humanized IgG [1], antibodies that bind to different epitopes and neutralize IL-13 bioactivity), mepolizumab (Anti IL-5 humanized IgG1 monoclonal antibody: Awaiting FDA and EBM approval), reslizumab (Humanized monoclonal anti-IL-5 antibody (IgG4/k): Phase III studies completed), benralizumab (Humanized, afucosylated monoclonal antibody against IL-5Ra), brodalumab (Human IL-17RA-specific monoclonal antibody), secukinumab (AntiIL-17 monoclonal antibody that selectively neutralizes IL- 17A), eculizumab (mAb (a hybrid of IgG2 and IgG4 Fc portion) cleaves and deactivates $\mathrm{C5})[2]$.

We showed that, omalizumab (Blocks IgE to Fc-RI-Ig fusion protein and membrane Fc-RI: Approved FDA and EMA) treatment decreases eosinophil, basophil and ECP levels in patients with SPA and it is effective in treating asthma in patients with severe cardiovascular complications. Targeting the interleukin (IL) pathway has led to the formulation of monoclonal antibody therapies against IL 4 (dupilumab, AMG 317, altrakincept, pascolizumab), IL5 (mepolizumab, benralizumab), and IL13 (pitrakinra, anrukinzumab, tralokinumab, lebrikizumab) IL17 (brodalumab, secukinumab), which are cytokines underlying the eosinophilic inflammation in SPA. These treatments will hopefully become available for patients with SPA $[1,3]$.

\section{References}

1. Yalcin AD (2015) Advances in anti-IgE therapy. Biomed Res Int :317465.

2. Mitchell PD, El-Gammal AI, O'Byrne PM (2016) Emerging monoclonal antibodies as targeted innovative therapeutic approaches to asthma. Clin Pharmacol Ther 99: 38-48.

3. Chung KF (2015) Targeting the interleukin pathway in the treatment of asthma. Lancet 386: 1086-1096. 